\title{
Paul Rudolph: arquitecturas dibujadas en el paisaje de Florida
}

\section{Paul Rudolph: portrayed architectures in Florida's landscape}

\author{
NOELIA GALVÁN DESVAUX \\ ANTONIO ÁLVARO-TORDESILLAS \\ MARINA JIMÉNEZ JIMÉNEZ
}

Noelia Galván Desvaux, Antonio Álvaro-Tordesillas y Marina Jiménez Jiménez "Paul Rudolph: arquitecturas dibujadas en el paisaje de Florida”,

ZARCH 10 (Junio 2018): 100-113

ISSN: 2341-0531. https://doi.org/10.26754/ojs_zarch/zarch.2018102934

Recibido: 15-2-2018 Aceptado: 9-5-2018

Resumen

La casa americana de la segunda mitad de los cuarenta, se convirtió en la protagonista de la arquitectura de la época como refugio de la vida del hombre tras la guerra. Para ello, muchos arquitectos, partiendo de las enseñanzas de Wright y de los maestros europeos emi grados, propusieron un espacio doméstico flexible y abierto a su entorno, donde poder reencontrar el contacto con el paisaje. Se trataba de poner de nuevo la casa en relación con la tierra, o así lo entendió Paul Rudolph en las viviendas que ideó para Florida, un entorno que comenzaba a establecerse como lugar vacacional del americano medio. Rudolph utilizó en sus arquitecturas el lugar como un elemento más de proyecto, y así lo muestran sus dibujos. A través de análisis de su grafismo podemos descubrir una serie de elementos que ponen de relieve el espacio en el que se asienta su arquitectura, tratando de recuperar la dimensión poética del paisaje.

Palabras clave

Paul Rudolph, arquitectura doméstica, paisaje, dibujo.

\section{Abstract}

The American house from the late 40s leaded the architecture of that period since it became shelter for human life after the war. With that in mind, and based on the teachings of Wright and the migrating European masters, many architects proposed a flexible domestic space open to their environment, where they could rediscover contact with the landscape. It was a matter of placing the house back in relation to the land, or at least that is how Paul Rudolph perceived it in the houses he designed for Florida, a setting that was starting to become established as a holiday destination for the average American. Rudolph understood the environment as one more element of his work, and so his drawings show. The analysis of his graphics reveals a series of elements that highlight the space where the architecture lays, in an attempt to retrieve the poetic dimension of the landscape.

Keywords

Paul Rudolph, domestic architecture, landscape, drawing

Noelia Galván Desvaux (Valladolid, 1980) Arquitecto por la ETS de Arquitectura de la Universidad de Valladolid (2003) y Doctor por la misma universidad (2012). Profesora Ayudante Doctor en el Área de la Expresión Gráfica Arquitectónica del Departamento de Urbanismo y Representación de la Arquitectura (ETSAVa) desde 2004. Miembro de los grupos de investigación Documentación, análisis y representación del patrimonio arquitectónico (U. Valladolid) y Pensamiento gráfico y narrativa arquitectónica (U. Alicante). Profesora en cursos de Doctorado, Máster y Posgrado en España e Italia. noeliagalvan@gmail.com

Antonio Álvaro-Tordesillas (Ciudad Real, 1973). Arquitecto por la ETS de Arquitectura de la Universidad de Valladolid (1999) y Doctor por la misma universidad (2008). Premio extraordinario de Tesis Doctoral (2010). Profesor Contratado Doctor en el Área de la Expresión Gráfica Arquitectónica del Departamento de Urbanismo y Representación de la Arquitectura (ETSAVa) desde 2004. Miembro de los grupos de investigación Documentación, análisis y representación del patrimonio arquitectónico (U. Valladolid) y Pensamiento gráfico y narrativa arquitectónica (U. Alicante). Profeso en cursos de Doctorado, Máster y Posgrado en España e Italia (Programa de Doctorado e Investigación Internacional "Architetture and urban phenomenology").

Marina Jiménez Jiménez (Ávila, 1972). Arquitecta (1998) y Doctora arquitecta (2009) por la Universidad de Valladolid, y Máster en Paisajismo (2016) por la Universidad Politécnica de Valencia. Desde 2000 profesora -acreditada a Contratada Doctora- en el área de Urbanismo y Ordenación del Territorio del Departamento de Urbanismo y Representación de la Arquitectura (ETSAVa). También ha sido docente en las áreas de urbanismo, expresión gráfica y proyectos de las Universidades de A Coruña (2013-2014) y la Lusiada (Oporto, 2009-2012). Miembro del Instituto Universitario de Urbanística, desde el que realiza numerosos proyectos I+D+i nacionales e internacionales (actualmente participa en la coordinación del proyec to europeo Marie-Curie H2020, urbanHIST) 
La relación entre arquitectura y paisaje ha sido abordada desde múltiples visiones, que permiten entender el inestable equilibrio entre las trazas de la existencia del hombre y su entorno. Pero la visión a plantear aquí trata de la simbiosis de ambos a través de la huella de la vida, concretándose en rastros y vestigios del que vive. Cabría afirmar que la arquitectura en el paisaje es una plasmación física de las acciones, hábitos y costumbres, y que es en ellos se encuentra la verdadera esencia del habitar.

Poco antes de los años cincuenta, la cultura dominante en la arquitectura abandonó definitivamente aquellas utopías de entreguerras que definían la vivienda como una máquina de vivir, entendiéndola más bien como el cascarón del hombre, tal como propondría Eileen Gray. A partir de esta época, comenzaron las investigaciones en torno al habitar humano, no sólo desde la arquitectura, sino también desde la filosofía y el arte; iniciativas todas encaminadas a la necesidad de retomar la idea de la habitación para construir la casa y para devolver al hombre al origen del habitar. Un habitar que no sólo debería atender a los modos de vida (hábitos, acciones y costumbres), sino también a las condiciones del lugar y del paisaje.

Los arquitectos americanos, que hasta ese momento habían estado inmersos en los planes estatales de vivienda, se adaptaron a una sociedad que reclamaba la nueva vida idílica tal y como mostraban las revistas y que se orientaba, principalmente, a los soldados que regresaban de la guerra. Un nuevo estilo de vida suburbana que "creó un potente sueño de riqueza doméstica que colisionó con la austera visión arquitectónica del Movimiento Moderno"1, instaurando el fallido modelo de los urban sprawls que se extendieron como una mancha de aceite en los suburbios de la ciudad americana. Pero junto a estos modelos fallidos nos encontramos con arquitectos como Paul Rudolph, que llegaron a desarrollar modelos de vivienda en perfecto equilibrio con el maravilloso entorno de Florida [fig. 1).

[Fig. 1] Paul Rudolph en Siesta Key, Sarasota, Florida. Fuente: Paul Marvin Rudolph Archive, Library of Congress, LC-DIG-ppmsca-39541.

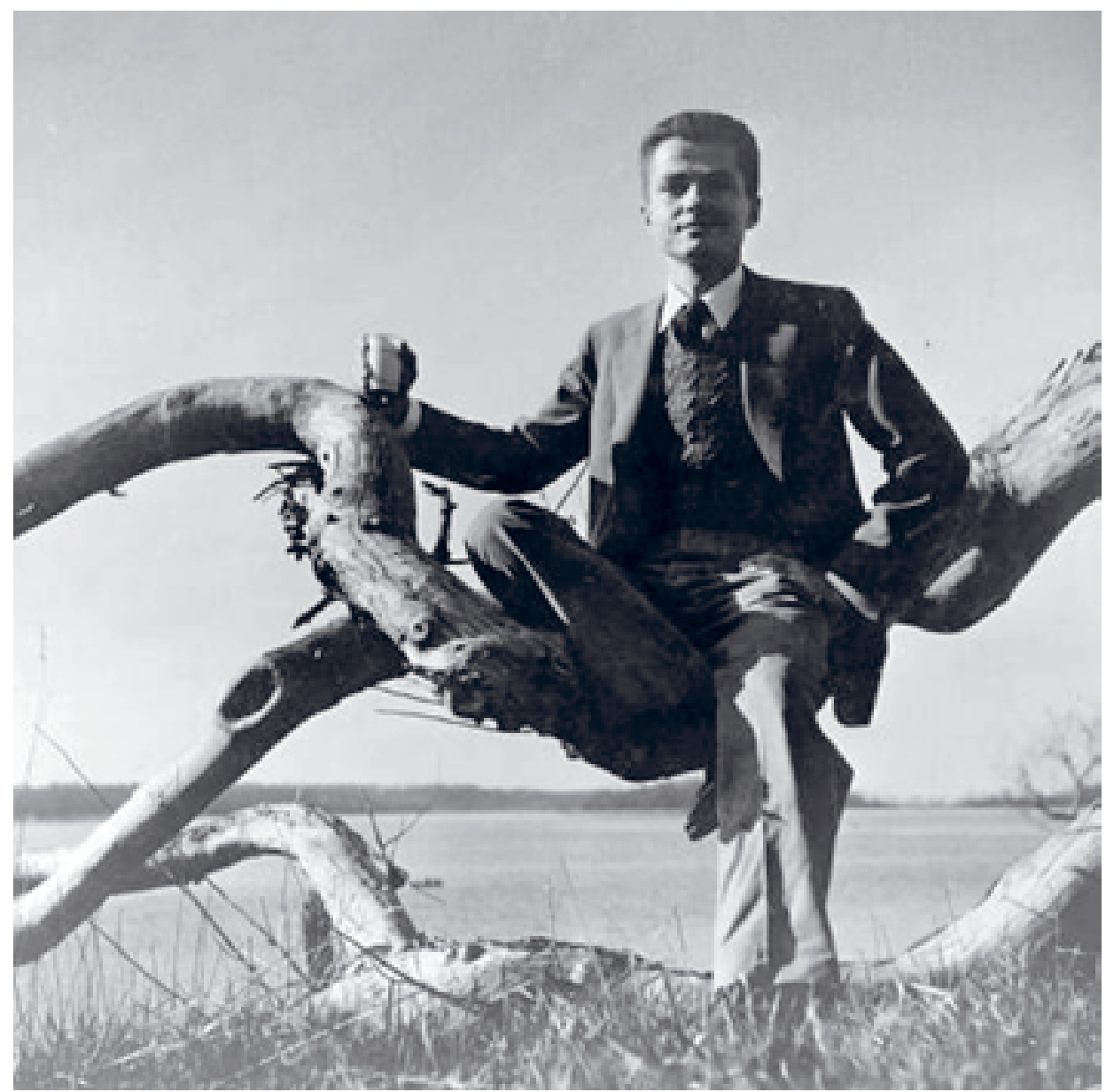




\section{Centenarios}

de la Tercera Generación

Centenaries of the

Third Generation

\section{NOELIA GALVÁN DESVAUX \\ ANTONIO ÁLVARO-TORDESILLAS \\ MARINA JIMÉNEZ JIMÉNEZ}

Paul Rudolph: arquitecturas dibujadas

en el paisaje de Florida

Paul Rudolph: portrayed architectures

in Florida's landscape
Ningún ejemplo mejor para estudiar esas nuevas relaciones que se establecen entre la arquitectura, los nuevos modos de vida y el lugar, que el amplio conjunto de viviendas unifamiliares que Paul Rudolph proyecta en la costa de Florida, fruto del optimismo económico y social que se desarrolló en los Estados Unidos tras el conflicto bélico.

Debemos recordar cómo las publicaciones especializadas, junto con los distintos fabricantes de materiales de la construcción, patrocinaron concursos con los que mostrar a las nuevas generaciones que era necesario refundar las bases de la vivienda para hacerla funcional, tecnificada y moderna. Las Case Study Houses y las vivienda de California llegaron a plasmar estos nuevos ideales del American way of life. Este modelo influiría en la nueva arquitectura de Florida, y en especial en la construida en la pequeña isla de Siesta Key, si bien la exuberante naturaleza y lo acotado del territorio darían lugar a unos ejemplos únicos.

\section{Florida y la escuela de Sarasota: The land of sunshine}

Paul Rudolph tomaría contacto con Florida en 1941, a través de su trabajo en el estudio de Ralph Twitchell, tras graduarse en arquitectura en el Alabama Polytechnic Institute y antes de incorporarse a la Marina durante la Guerra Mundial. Twitchell se había instalado en California en los años veinte, y no fue hasta los cuarenta cuando dejó atrás el clasicismo y el Art Decó en sus edificios. Con el fin de renovar su repertorio formal, Twitchell buscó la inspiración en la obra de Frank Lloyd Wright, y en concreto en algunas obras que el maestro americano había construido en Florida, coincidiendo así con las preferencias del joven Rudolph, que desde muy joven era un rendido admirador de la arquitectura de Wright ${ }^{2}$.

Tras licenciarse del servicio militar, y antes de volver a trabajar en el estudio de Twitchell, Rudolph, realizó sus estudios de postgrado Graduate School of Design de la Universidad de Harvard, que desde 1937 dirigía Walter Gropius, obteniendo el título de máster en arquitectura en 1947. Estos hechos son muy significativos para entender las primeras viviendas proyectadas por los dos arquitectos en 1947. Se podría decir que Rudolph y Twitchell aplicaron las enseñanzas de Wright con respecto a los materiales y el modo en el que la arquitectura se asienta en el lugar. Gropius $^{3}$ y otros maestros europeos como Breuer o Mies les ayudaría a desarrollar una nueva arquitectura adaptada a los ideales de la domesticidad moderna, que el fundador de la Bauhaus había plasmado en 1938 en su casa en Lincoln. Por último, los años de Rudolph en el ejército le permitieron conocer las ventajas de los nuevos materiales y las posibilidades que ofrecían las innovaciones técnicas derivadas de la industria bélica ${ }^{4}$.

A partir de estas premisas Rudolph y Twitchell establecieron el modelo de lo que iban a ser sus casas de Florida a través del concurso de la Revere Quality House de $1948^{5}$ [fig. 02]. Este concurso resultó ser el punto de encuentro de los cas veinte arquitectos que conformaron la famosa escuela de Sarasota, defendiendo un estilo propio, que marcaría la arquitectura del área de Florida ${ }^{6}$, transformando el modo de vida de la zona.

En esa época Sarasota, y en particular Siesta Key, donde Rudolph construyó la mayor parte de sus obras, era un entorno natural con cayos y playas tropicales que apenas había desarrollado su potencial turístico. La sociedad americana de los cincuenta, en busca del feliz verano perpetuo, transformó Florida en The land of sunshine [fig. 3], de manera que pronto comenzaron a proliferar las casas de vacaciones, respondiendo al nuevo modo de vida del americano medio tras la guerra. 

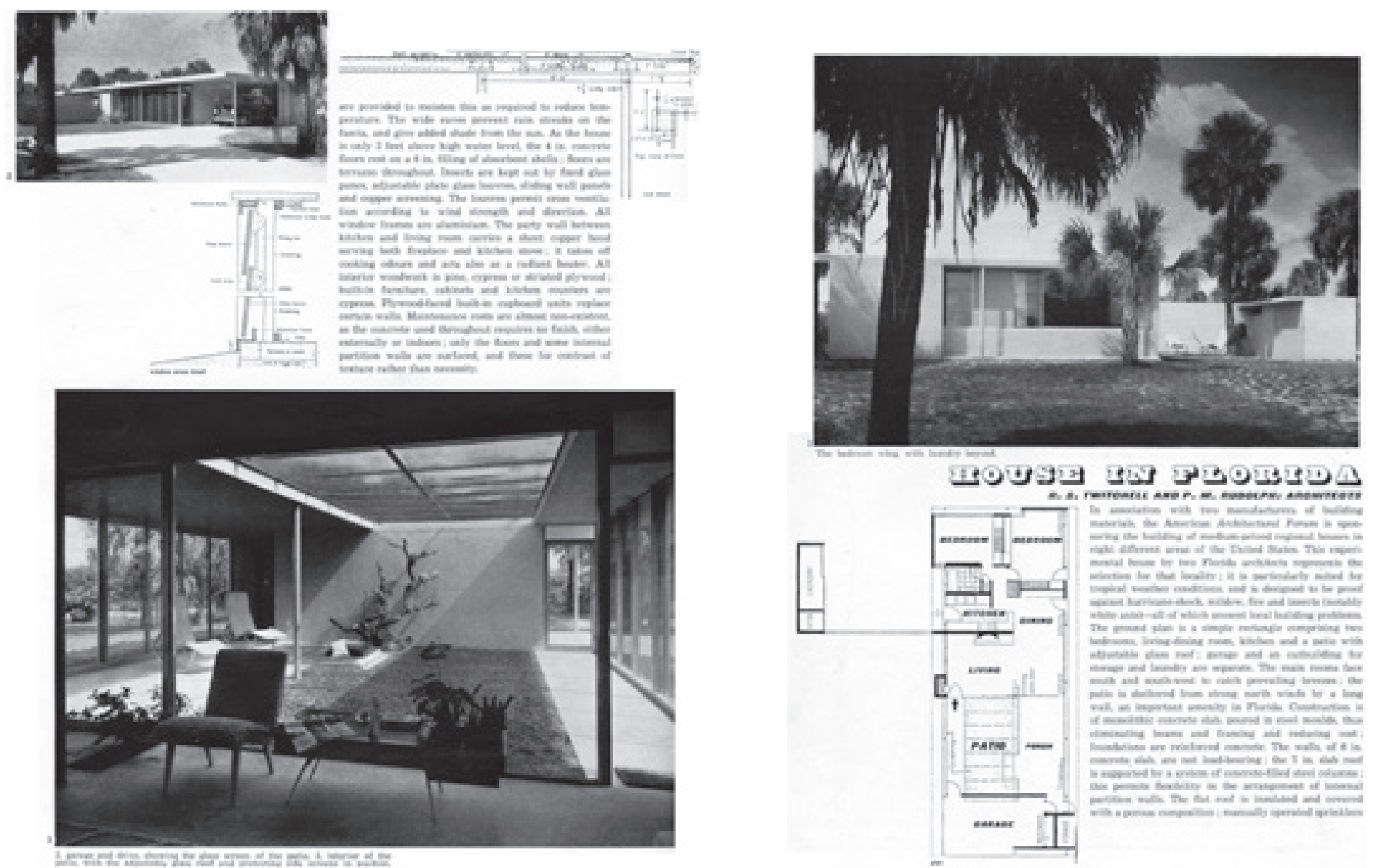

[Fig. 2] Revere Quality House publicada en Architectural Review (junio de 1949). Fuente: Paul Rudolph, "Revere Quality House", Architectural Review (junio 1949): 287-288.

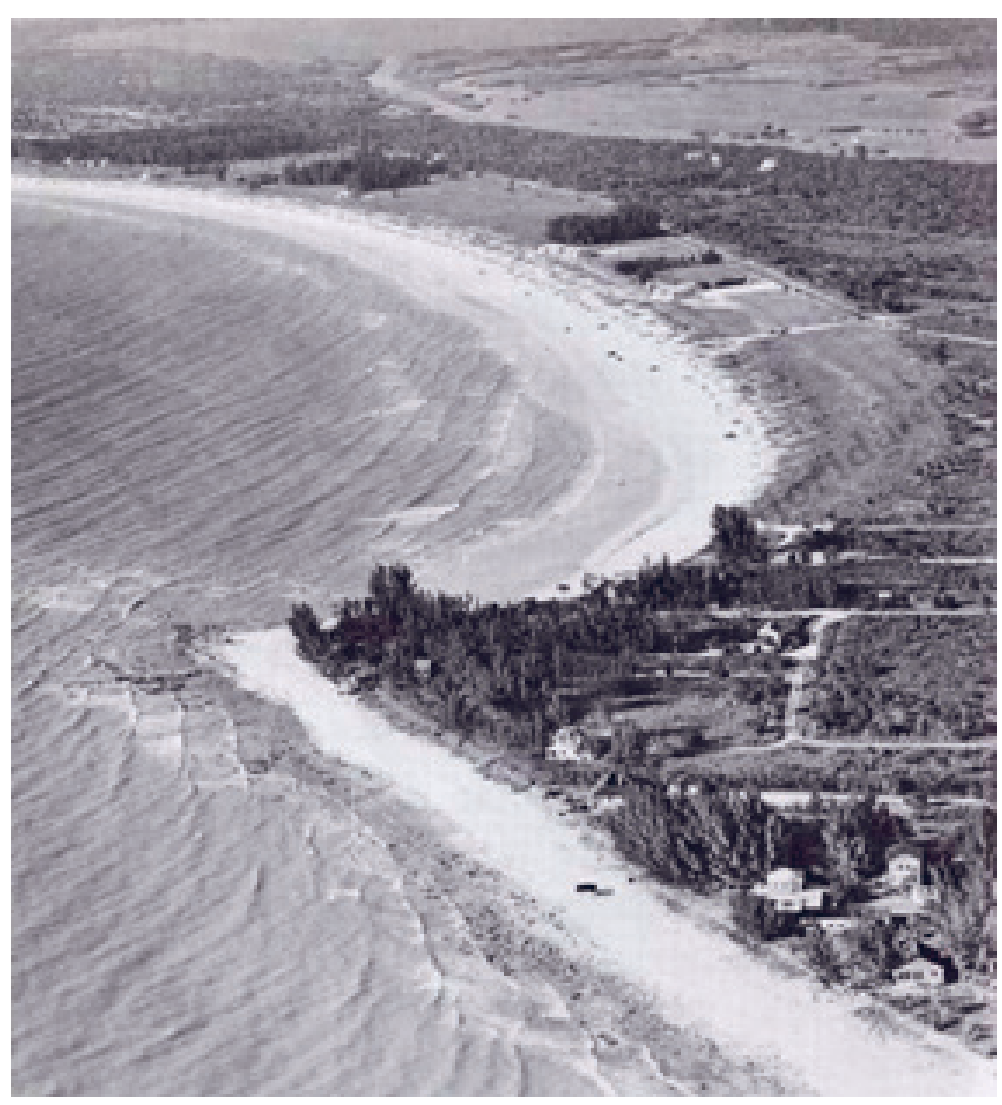

[Fig. 3] Vista aérea de Siesta Key, 1950. Fuente: Del Marth, Yesterdays Sarasota (Sarasota: E. A. Seemann Pub, 1973).

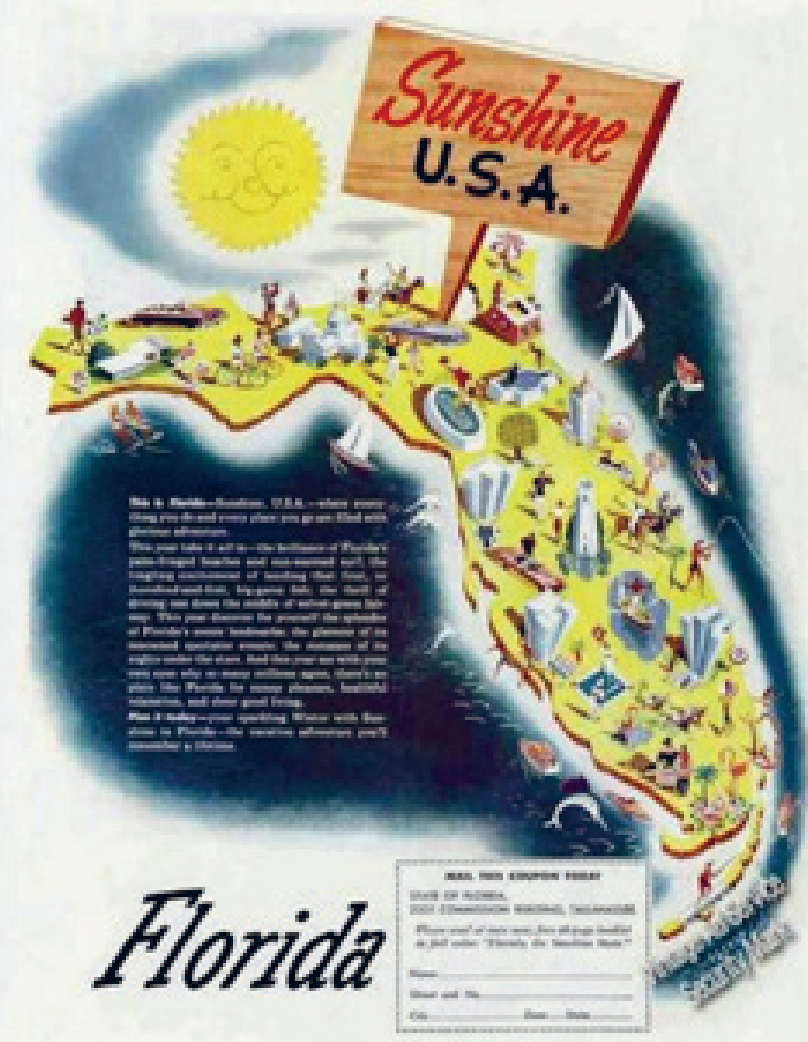

[Fig. 4] Florida Sunshine USA, 1950. Fuente: "Sunshine Usa", Nice Graphics (1950). 


\section{NOELIA GALVÁN DESVAUX \\ ANTONIO ÁLVARO-TORDESILLAS \\ MARINA JIMÉNEZ JIMÉNEZ}

Paul Rudolph: arquitecturas dibujadas

en el paisaje de Florida

Paul Rudolph: portrayed architectures

in Florida's landscape
7 Christopher Domin, Paul Rudolph: the Florida houses (New York: Princeton Architectural press, 2002), 42.

8 Las dos primeras casa del barrio de Sandy Hook en Siesta Key fueron diseñadas por Mery Hook a principio de los cincuenta, la tercera la proyectaría Paul Rudolph. Curiosamente, Hook fue la primera que, en esa zona, empleó el paisaje como elemento de proyecto. Además, Rudolph utilizaría los mismos paneles de hormigón prefabricado de las viviendas diseñadas por Hook en su Revere Quality House. Lorrie Muldowny, "Siesta Key Architecture a Natural", Sarasota History Alive, $<$ http://www.sarasotahistoryalive.com/history/ articles/siesta-key-architecture-a-natural/> (consultada el 10 de Enero de 2017).

9 Kenneth Frampton, "Towards a Critical Regionalism: six points for an architecture of resistance", en The anti-aesthetic: essays on postmodern culture (Seattle: Bay Press, 1983), 16-30. A propósito de esta cuestión, Rudolph desestimó el regionalismo como identidad. Ve Timothy M. Rohan, The Architecture of Paul Rudolph, (Cambridge: Yale University Press, 2014), 278

10 Domin, Florida houses, 53.

11 Scott Bennion, "In the manner of Hugh Ferriss and Paul Rudolph", RIBA Journal 120 (agosto 2013): 33.
El desarrollo de Siesta Key [fig. 4], aunque vinculado al boom turístico e inmobiliario posterior, posee un proceso particular ligado a la conexión de su arquitectura con la naturaleza y al clima de Florida. Ya en 1937 la arquitecta Mary Hook, formada en la Ecole des Beaux Arts de París, proyectó el Whispering Sands Inn, un refugio para artistas, escritores y arquitectos ${ }^{7}$. La visión paisajística de Hook caló hondo en la arquitectura de Rudolph ${ }^{8}$, cuyos proyectos en Siesta Key trataron de conservar la difícil armonía entre la modernidad de su arquitectura y la apabullante naturaleza de su paisaje.

\section{La dimensión poética del dibujo}

Paul Rudolph llegaría a construir en Florida unas cincuenta viviendas durante los siguientes veinte años. Su arquitectura doméstica se desarrolló conforme a lo que Kenneth Frampton ha denominado como el regionalismo crítico ${ }^{9}$ : una arquitectura apoyada en el entorno físico y social, y en su tradición, como base para transformar el estilo internacional aséptico y racional.

Esta nueva arquitectura, cuyos objetivos eran la libertad, la relación con el entorno, las nuevas tecnologías o la mejora de la vida de sus habitantes, fue abordada por Rudolph con formas simples y espacios abiertos. Viviendas claras, rotundas y modernas, pero que no acababan de destacar en su representación gráfica, ya que su riqueza de formas se perdía en los usuales dibujos planos y poco atractivos. Rudolph, consciente de este problema, se propuso desarrollar un nuevo sistema gráfico en el que su dibujo reflejara tanto su arquitectura como su inserción en el paisaje. Para ello acudió a nuevos enfoques perspectivos, secciones fugadas o a dibujos increíblemente precisos en sus texturas, pensados siempre para la mejor comprensión de sus viviendas.

La sensibilidad del arquitecto hacia la arquitectura y el lugar fue el inicio de un sistema gráfico propio, donde la línea negra sobre el fondo blanco fue la protagonista. Parece que en esta decisión influyó la facilidad de reproducción en blanco y negro en las revistas de la época ${ }^{10}$, frente a otros sistemas más coloristas o pictóricos que se mostraban desvaídos al trasladarse al papel impreso. Rudolph recurrió entonces a las líneas y punteados para representar las texturas de los distintos materiales, a dramáticos claroscuros con los que mostraba la fuerte luminosidad de Florida y el efecto en sus viviendas, y a visiones detalladas de la naturaleza que rodeaba la casa, con sus omnipresentes cerezos japoneses y la presencia constante del agua [fig. 05].

Sus dibujos muestran así una gran sensibilidad y visión espacial para imaginar escenas, capaces de transportar al observador a lugares inventados, donde la arquitectura y la naturaleza se interrelacionan en un equilibrio perfecto. Los dibujos nos hablan de una nueva manera de habitar, de un modo de vida relajado. Son visiones poéticas de arquitecturas para la vida lúdica del nuevo habitante americano y los personajes que las habitan también toman esta nueva condición, haciéndonos partícipes de sus espacios.

Sus dibujos también reflejan algo de su aprendizaje con Walter Gropius en Harvard, al aunar en sus axonometrías el análisis de la vivienda, su emplazamiento, el sistema constructivo, la estructura o los materiales [fig. 6]. Estos enfoques son especialmente interesantes ya que en ellos vemos la dualidad de su arquitectura doméstica y de su lenguaje gráfico; sea este representativo, inspirado en grandes dibujantes como Wright y Hugh Ferris ${ }^{11}$, o conceptual, basado en los principios de la Bauhaus, pero siempre en el contacto con la naturaleza, regional e indígena como el mismo lo definió. 

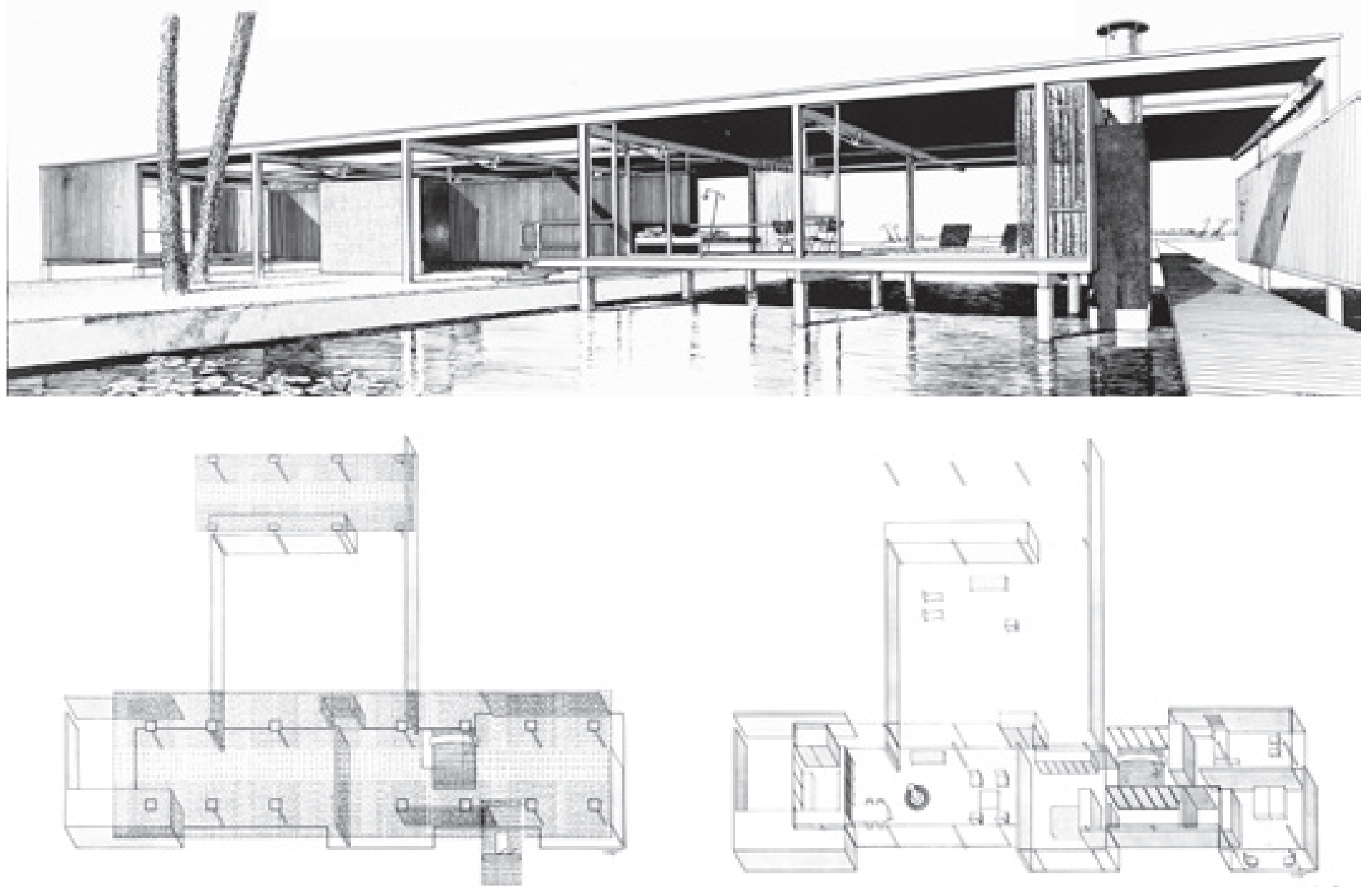

[Fig. 5] Paul Rudolph, Finney Guest House, Siesta Key, Florida (no ejecutada), 1947. Fuente: Paul Rudolph, Finney guest house, 1947. Archivo online del Library of Congress, Paul Marvin Rudolph Archives, LC-USZ62-135199.

[Fig. 6] Paul Rudolph, Burnette Residence, Sarasota, Florida, 1949-50. Fuente: Paul Rudolph, Burnette Residence, 1949-50. Archivo online del Library of Congress, Paul Marvin Rudolph Archives, LC-USZ62-135193 y LC-USZ62-135192.

12 "Rudolph and I never could keep up the same quality of conversation because Rudolph is an artist. That really, I suppose, has been his problem throughout life. He is a real artist. $\mathrm{He}$ knew what he wanted, knew what shapes he wanted. And he was more interested in those than he was in the - although there's nothing wrong with his intellect. He's a great teacher, as you know. Oh, my God, you were his student, weren't you? But somehow you wouldn't put him in that class of intellectural". Philip Johnson y Robert A. M. Stern, The Philip Johnson Tapes: Interviews by Robert A.M. Stern (New York: Monacelli Press, 2008) 99-100.

13 Laurence Scarpa, Paul Rudolph: Metaphors, Paradoxes, Contradictions and Abstractions (Cambridge: Yale Press, 2009).

14 Christian Norberg-Schulz, Genius loci: towards a phenomenology of architecture (Nueva York: Rizzoli International Publications, 1980).

15 Peter Zumthor, Atmosferas (Barcelona: Gustavo Gili, 2006).

16 John Zinsser, "Staying Creative; Artistic Passion Is a Lifelong Pursuit - and These Mature Masters Prove the Point. (Otto Luening, Elizabeth Catlett, Paul Rudolph)", 50 Plus 25 (diciembre 1985): 55
Lawrence Scarpa, colaboradora de Rudolph, explica así su proceso de proyecto a través del dibujo, entendiendo que de sus trazos brota la arquitectura. Los dibujos eran medidos y precisos porque así lo eran sus proyectos. No tenían el afán de ser mostrados como podría parecer inicialmente, si no que eran fruto, en palabras de Philiph Johnson ${ }^{12}$, de la velocidad de su mente.

"While working at his desk, he would move his hand over his drawing in such a way that he could better understand the actual scale and what it might be like to occupy the drawing, as if it were an actual building. He seemed as though he was actually inside the drawing. He would touch with his eyes and see with his hands. He always included human figures in his drawing, particularly in section and elevation drawings, to further understand how the scale of the space related to an actual person. For Rudolph the drawing was a building at full scale. This concept was the origin of his creative process"13.

Para Paul Rudolph, el dibujo era también el medio a través del cual reflexionar sobre cómo la arquitectura incide y transforma la naturaleza en paisaje, gracias a "la dimensión poética que surge cuando las construcciones aúnan las propiedades del lugar y las acercan al hombre"14. Esa dimensión poética del dibujo brotaba a través de su capacidad de evocación de lo intangible -de una atmósfera ${ }^{15}$ o de un gesto-, una categoría estética difícilmente representable ya que responde a las emociones más íntimas. Para Rudolph, que acostumbraba a dibujar de pie frente a un tablero vertical como los artistas, el medio -el dibujo- era la respuesta:

"I try to find a graphic means of indicating what's happening to the space. Space can move quickly or slowly. It can twist and turn. Space extends the dynamics of any building, because if the thrusting and counter-thrusting of the spaces aren't balanced, then people feel unstable, the building doesn't feel harmonious"16. 
ZARCH No. $10 \mid 2018$

\section{Centenarios}

de la Tercera Generación

Centenaries of the

Third Generation

\section{NOELIA GALVÁN DESVAUX \\ ANTONIO ÁLVARO-TORDESILLAS \\ MARINA JIMÉNEZ JIMÉNEZ}

Paul Rudolph: arquitecturas dibujadas

en el paisaje de Florida

Paul Rudolph: portrayed architectures

in Florida's landscape
A vista de pájaro: colocar casas en el cielo

Y así, a través del dibujo, comenzaron a surgir sus visiones del paraíso inhabitado de Florida, donde cuestiones como el emplazamiento, la relación con el paisaje, el clima y la psicología del espacio interior y exterior, unido a la funcionalidad, los materiales y el espíritu de la época ${ }^{17}$ fueron los factores determinantes de su arquitectura doméstica. Empezaron a surgir lo que se puede entender como "objetos abstractos sobre el fondo de idílicos paisajes"18, influenciados tanto por el emplazamiento como por las enseñanzas funcionalistas de los maestros europeos. Su principal propósito era sustantivar el entorno natural y ubicar en él la casa, creando así un lugar. Rudolph utilizó sus edificios para definir el paisaje y para ello optó por mostrarlo desde el aire. El porqué de esta decisión tiene que ver con su intento de explicar cómo podía lograr una perfecta armonía entre su arquitectura y el paisaje circundante; una armonía que no se alcanzaba mediante una mimetización pintoresca, sino mostrando como sus edificios actuaban como elementos positivos que realzaban la belleza de las riberas de Siesta Key.

[Fig. 7] Paul Rudolph, Alex Miller Residence (no ejecutada), 1947. Fuente: Paul Rudolph, Alex Miller residence, 1947. Archivo online del Library of Congress, Paul Marvin Rudolph Archives, LC-DIG-ppmsca-03525.

17 Paul Rudolph, "The Six Determinants of Architectural Form”, Architectural Record 120 (octubre 1956): 183-190.

18 Débora Domingo, "La modernidad sureña: Paul Rudolph en Florida", en Casa por casa: reflexiones sobre el habitar (Valencia: General de Ediciones de Arquitectura, 2009), 99.

19 Kazimir Malevich, El mundo no objetivo (Aracena: Gegner, 2013).
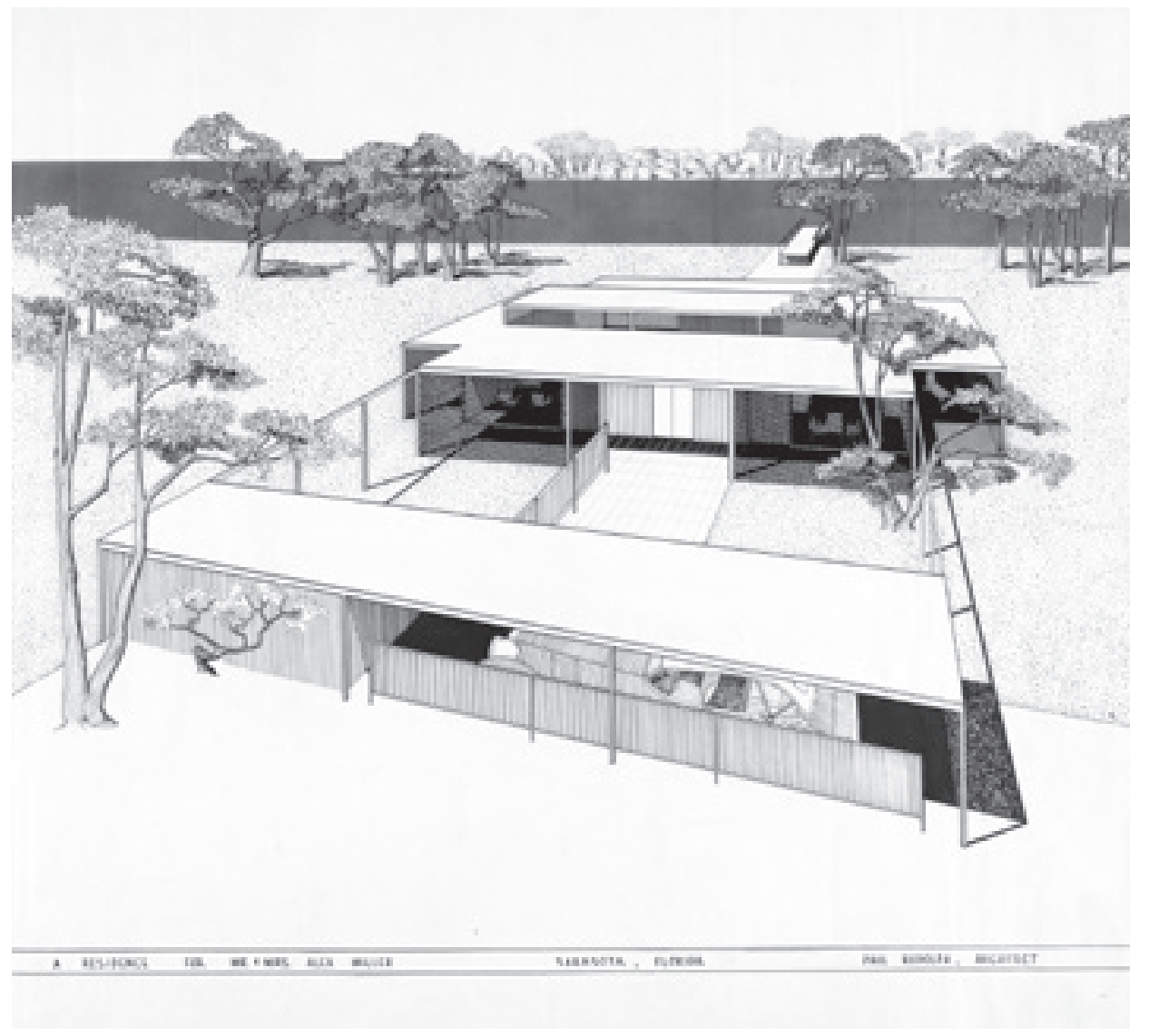

Además, al observar sus primeros dibujos, como el que el arquitecto crea para la casa Alex Miller de 1947 [fig. 7], nos damos cuenta de que Rudolph manipula la perspectiva, utilizando esta vista de pájaro para acentuar el dramatismo y la poética de la construcción, desplegando cuidadosamente las masas forestales para evocar su ideal de integración en el lugar.

Es conocido que la percepción humana gusta de estas visiones cercanas a las axonometrías, probablemente porque se perciben de modo similar a cuando tomamos una maqueta en nuestras manos, y refuerzan el sentido de control y de posesión de lo dibujado. La perspectiva aérea, según Malevich ${ }^{19}$, es un fenómeno específicamente genuino del arte del siglo XX que proviene de los viajes en aeroplano y de la fotografía aérea. De modo que el recurso a la vista de pájaro por Rudolph respondería a un nuevo modo de ver y percibir la realidad en su época, y a su intento por difundir su idea de una nueva arquitectura doméstica. 

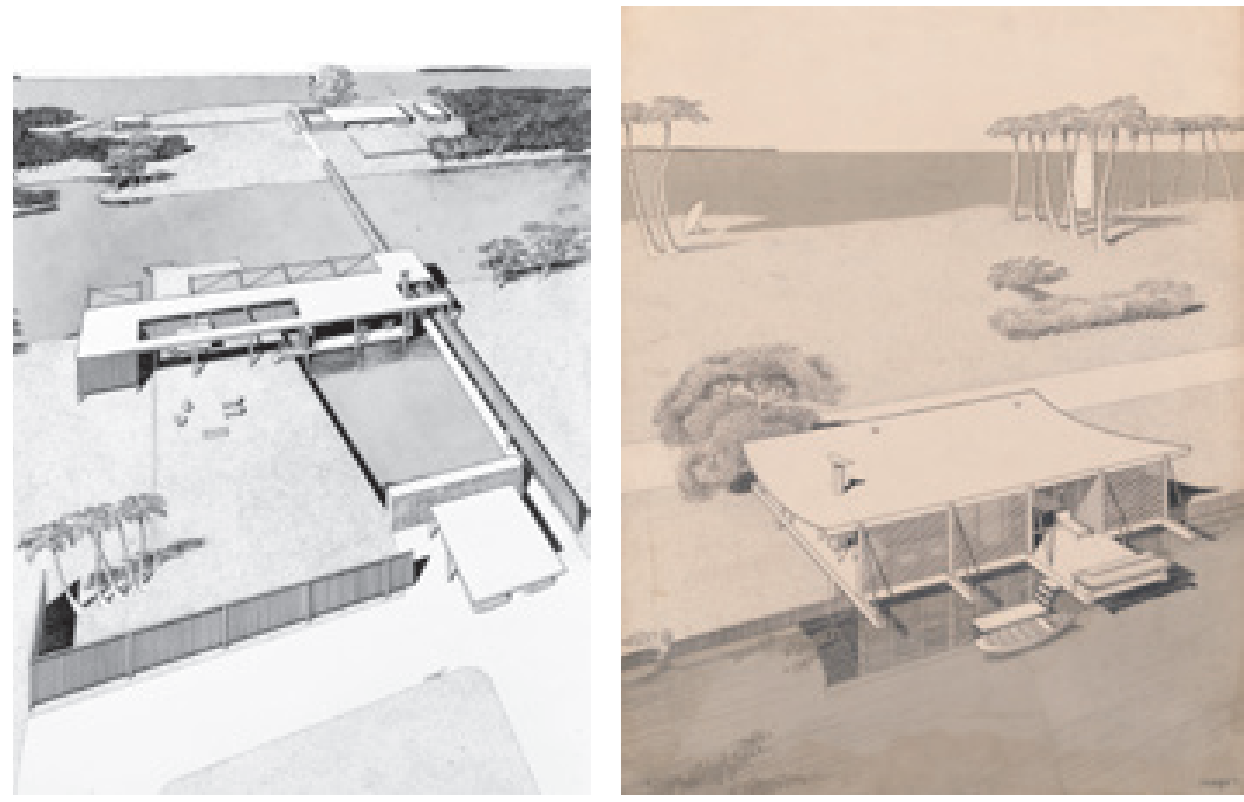

[Fig. 8] Paul Rudolph, Finney Guest House, Siesta Key, Florida (no ejecutada), 1947. Fuente: Paul Rudolph, Finney guest house, Siesta Key, Florida (proyecto), 1947. Archivo online del Library of Congress, Paul Marvin Rudolph Archives, LC-USZ62-135201.

[Fig. 9] Paul Rudolph, Cocoon House (Healy Guest House), Siesta Key, Florida, 1950. Fuente: Paul Rudolph, Cocoon house (Healy guest house), Siesta Key, Florida, 1950. Archivo online del Library of Congress, Paul Marvin Rudolph Archives, LC-DIGppmsca-39713.
20 Philip Drew, Third Generation: The Changing Meaning of Architecture (London: Pall Mall Press, 1972), 44.

21 Sigfried Gideon, Espacio, tiempo y arquitectura (Madrid: Dossar, 1978).
Por otro lado, la perspectiva aérea permite comprender la relación entre el entorno y la arquitectura desde una posición ventajosa que acerca al territorio. En sus casas, como la Finney Guest House de 1947 [fig. 8] o la casa Cocoon de 1950 [fig. 9] existe una intensa búsqueda de la adecuación al lugar, ya que Rudolph crea un paisaje propio, drenando algunas zonas e inundando otras. Hace que las viviendas se relacionen con el agua y se eleven sobre esta o se posen en su orilla. Crea pasarelas que conectan las distintas lenguas de tierra, o embarcaderos con vistas a la bahía. Estrategias proyectuales que solo se pueden mostrar mediante las vistas aéreas.

"Quiero colocar casas en el cielo", decía Rudolph, y para ello proyecta viviendas sobre el terreno como si tan sólo construyese la cubierta. Un plano que divide el cielo y la tierra y que cobija al hombre, apoyada sobre unos pocos puntos como la Walker Guest House de 1953. Bajo esta cubierta se encontraba la casa, referencia constante a la horizontalidad y a su imbricación con el plano del suelo. Como afirma Philiph Drew "Ios límites de la plataforma y las caras internas de los tejados determinan la transición entre la arquitectura y el paisaje"20.

La cubierta se despega del suelo progresivamente y abre sus alas al aire con formas sinuosas -como sucede en la Hook Guest House de 1953-, o mediante los lucernarios escamoteables -como en la Cohen Residence de 1953-. Estas últimas viviendas pertenecen ya a la etapa en la que Rudolph a comenzado a trabajar en solitario, planteando una arquitectura doméstica que se cuestiona los límites de funcionalismo, y explora formas más orgánica siguiendo las pautas del entorno.

\section{Sobre el plano del suelo: objetos en el paisaje}

La evolución de la cubierta de sus casas de Florida se desarrolló en paralelo al modo en el que estas se van elevando del suelo. Si bien es cierto que Rudolph en sus últimas casas trató de retomar el contacto con el terreno, en un intento por desarrollar la idea de asentamiento primigenio a través del espacio del inglenook.

Al igual que las casas usonianas de Wright, las primeras viviendas de Siesta Key se disponen directamente sobre la tierra, lo que les otorga una de sus características principales: la continuidad espacial. Rudolph era buen conocedor del concepto de simultaneidad espacial que Sigfried Gideon había enunciado en Space Time and Architecture $^{21}$, y sabe aplicar sus ideas a sus proyectos. Eliminando las distinciones entre interior y exterior, la casa se convertía en un umbral, que se nos presenta como una celebración de la vida doméstica. 
ZARCH No. $10 \mid 2018$

\section{Centenarios}

de la Tercera Generación

Centenaries of the

Third Generation

\section{NOELIA GALVÁN DESVAUX \\ ANTONIO ÁLVARO-TORDESILLAS \\ MARINA JIMÉNEZ JIMÉNEZ}

Paul Rudolph: arquitecturas dibujadas

en el paisaje de Florida

Paul Rudolph: portrayed architectures

in Florida's landscape

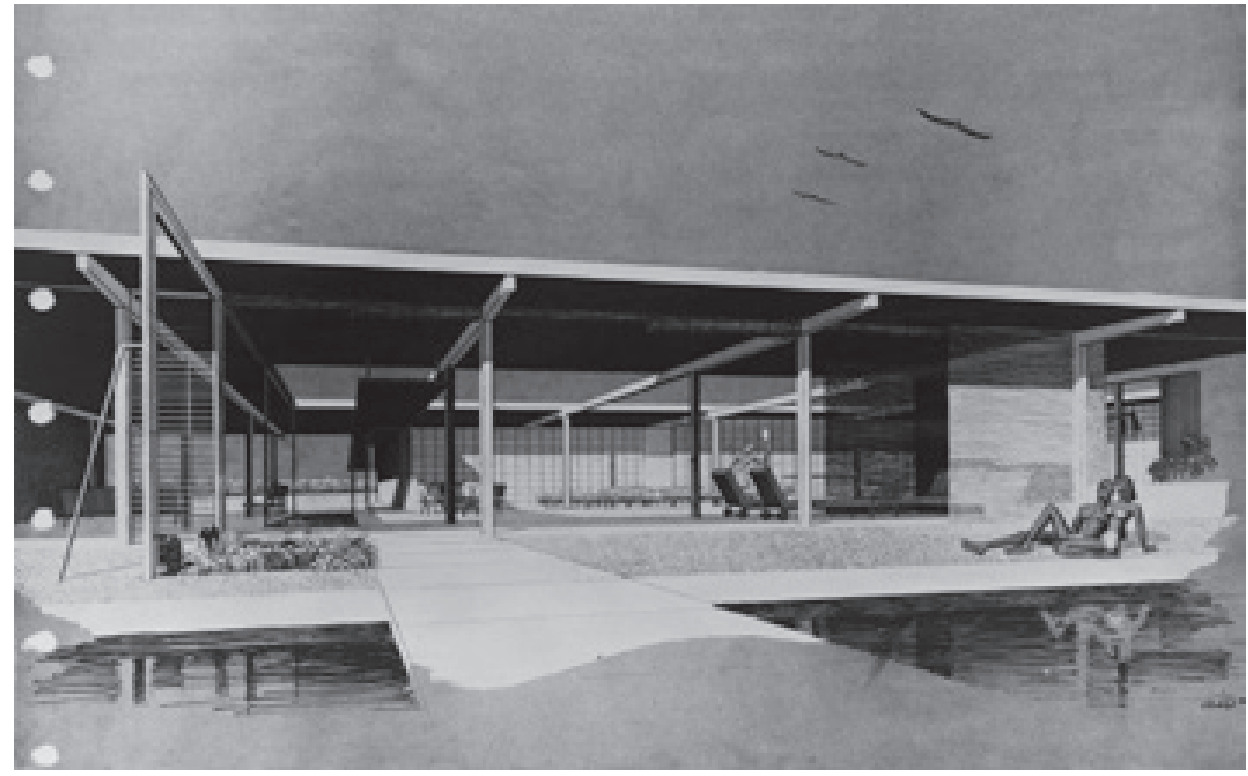

La transición entre el terreno y el interior resulta de la caracterización del pavimento, y lo que ocurre en esta conversión demuestra la condición horizontal de las casas [fig. 10]. La disolución del umbral se realiza a través pocos elementos; unos muros, el suelo y la cubierta, pero sobre todo se lleva a cabo en los espacios intermedios. Esta actitud de Rudolph frente al plano del suelo supuso una evolución de su lenguaje formal ${ }^{22}$, en cuanto respuesta a peculiaridades permanentes del lugar dentro de estas casas de Florida.

Pero también una evolución de su lenguaje gráfico, ya que va a utilizar aquí un nuevo sistema de dibujo que instauró como su sello personal a partir de este momento: la sección fugada. Según Reyner Banham ${ }^{23}$, estas secciones y muchos de sus dibujos de gran tamaño, que alcanzaban un grado de complejidad muy elevado, eran creados por Rudolph para sí mismo, y no como dibujos de presentación para sus clientes. Actuando así, controlaba el proceso de representación de sus proyectos, ya que el dibujo era parte integral de su método de diseño y no lo delegaba en los dibujantes de su estudio.

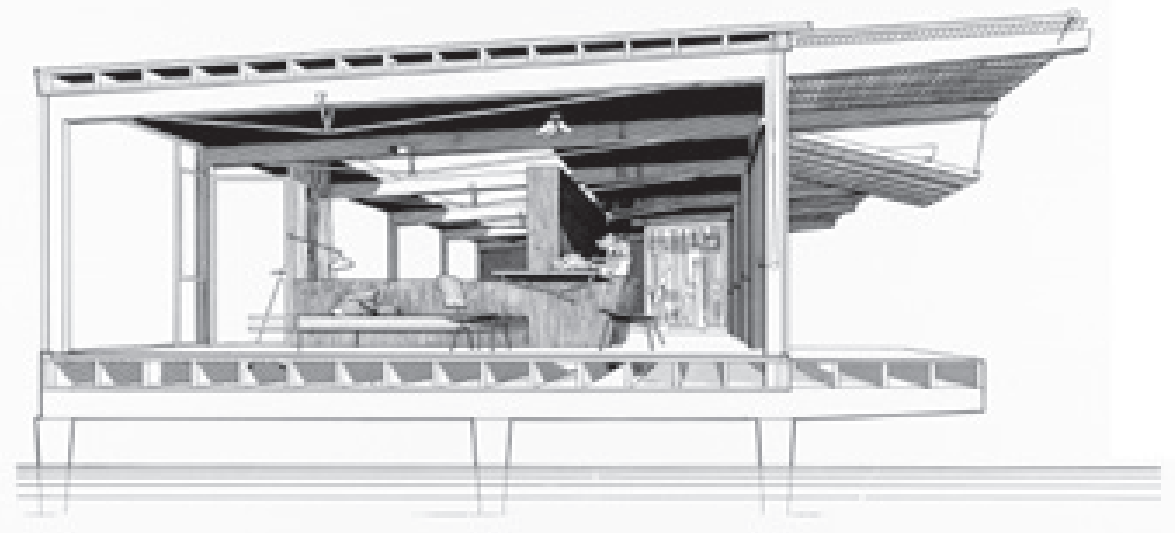

En cualquier caso Rudolph desarrolló un estilo de dibujo personal que fue fundamental para definir y modelar el espacio ${ }^{24}$. Y en él, la sección le sirvió como herramienta esencial de diseño para comprender los materiales, la estructura y la lógica tectónica del proyecto. Algo que podemos comprobar en el dibujo de la sección constructiva de la Finney Guest House, en la que lo tecnológico se mezcla con el maravilloso manejo de las texturas interiores, y con el estudio de la luz y de la sombra mediante el empleo de tramas y rallados en los refinados espacios [fig. 11]. 
[Fig. 12] Paul Rudolph, Milam Residence, Ponte Vedra Beach, Florida, 1959. Fuente: Paul Rudolph, Milam residence, Ponte Vedra Beach, Florida. 1959. Archivo online del Library of Congress, Paul Marvin Rudolph Archives, LC-USZ62-135188.
25 Timothy M. Rohan, "Rendering the Surface: Paul Rudolph's Art and Architecture Building at Yale", Grey Room 1 (otoño, 2000): 90.

26 Yukio Futagawa, Paul Rudolph: Architectural Drawings (Minnesota: Architectural Book Publishing, 1977).

27 Miguel del Rey Aynat, "De espacios y lugares en arquitectura”, Vía arquitectura 6 (1999): 60.

28 Juan Navarro Baldewerg, La habitación vacante (Valencia: Pre-textos, 1999).

29 Edmund Husserl, Ideas relativas a una fenomenología pura y una filosofía fenomenológica (Barcelona: Fondo de Cultura Económica, 1997).

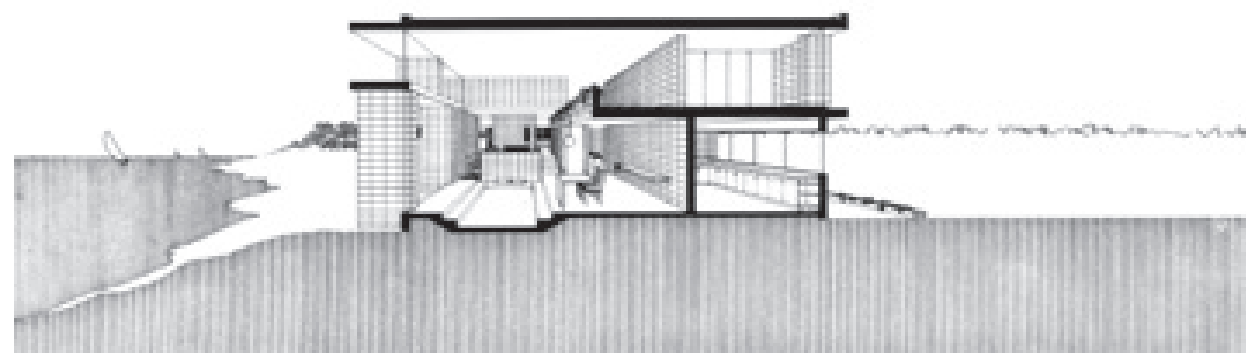

El empleo de las tramas en los dibujos de Rudolph deriva de la técnica artística del grabado y de la xilografía. Es posible que le llegase al arquitecto a través de un manual de finales de los años cuarenta -Scratchboard Drawing- que conservaba en su colección ${ }^{25}$. El esgrafiado era un sistema muy utilizado en la publicidad de la época por su buena reproducción en las revistas y periódicos.

Rudolph adaptó esta técnica de pluma y tinta a su dibujo, lo que le requería un gran control de la mano y un conocimiento muy preciso del objeto a trazar. Sus secciones en perspectiva, representadas en tres pesos de pluma diferentes, solían trabajarse con sombreados cubiertos con líneas verticales. Estas tramas representaban como norma general distintos materiales, que en muchos casos fueron la fuente de inspiración de las superficies de sus edificios construidos [fig. 12] ${ }^{26}$. La representación de superficies con múltiples líneas paralelas aportaba a la composición formal calidad atmosférica y una profundidad y riqueza que exigía una mirada más cercana.

\section{La vida en una estampa: idílicos paraísos}

Algunos temas de los analizados hasta aquí son invariantes en la primera obra domestica de Rudolph: la conexión con el paisaje imbuida en objetos tecnológicos, el dibujo como medio de proyecto y su representación como entendimiento de la arquitectura, la recuperación de los principios del lugar y su transformación en una modernidad regional.

Todos ellos responden a cualidades de las cosas, pero en la arquitectura de Rudolph hay algo más que es difícil explicar a través del medio físico o de sus representaciones gráficas. En los dibujos y las imágenes de sus casas hay algo efímero, que otorga una sensación de plenitud en sus deseos de lograr una perfecta armonía entre sus edificios y su entorno.

"El lugar se entiende como aquello que fluye en una atmósfera y que se materializa en relaciones concretas entre las cosas, entre los accidentes geográficos, entre el hombre y la naturaleza"27. En el lugar la arquitectura se conforma a través de ideas que responden a vínculos fenomenológicos, tal como afirmaría Juan Navarro Baldewerg ${ }^{28}$.

Representar la vivencia de una obra es tarea ardua, a pesar de que los teóricos del arte han dedicado capítulos completos a esta materia ${ }^{29}$. El problema radica en ser capaz de mostrar un espacio vivido, de introducir el transcurso del tiempo, los fenómenos atmosféricos, las sensaciones y experiencias; y hacerlo desde el papel para crear desde el dibujo la atmosfera de la arquitectura. 


\section{Centenarios}

de la Tercera Generación

Centenaries of the

Third Generation

NOELIA GALVÁN DESVAUX

ANTONIO ÁLVARO-TORDESILLAS

\section{MARINA JIMÉNEZ JIMÉNEZ}

Paul Rudolph: arquitecturas dibujadas en el paisaje de Florida

Paul Rudolph: portrayed architectures

in Florida's landscape
Rudolph, dibujante experimentado y más que capaz, acudió a un recurso gráfico que le permitió sugerir el modo de vida y el entorno que rodeaba a sus arquitecturas, y que literalmente parece que "flotan en el ambiente". Para ello trazaba perspectivas frontales que presentan reminiscencias a las estampas japonesas de Hiroshige, en las que se recorre el dibujo a través de los diversos planos de profundidad que se van superponiendo en el mismo.

Leonardo da Vinci definió este tipo de dibujos como perspectivas atmosféricas, ya que en ellas se entiende el paisaje a través de la variación de tonos que surgen al alejarse en ellos. El efecto se logra mediante la sucesión de matices entre los distintos planos, debido al efecto que la atmósfera tiene sobre la apariencia de un objeto, tal como se ve desde la distancia.

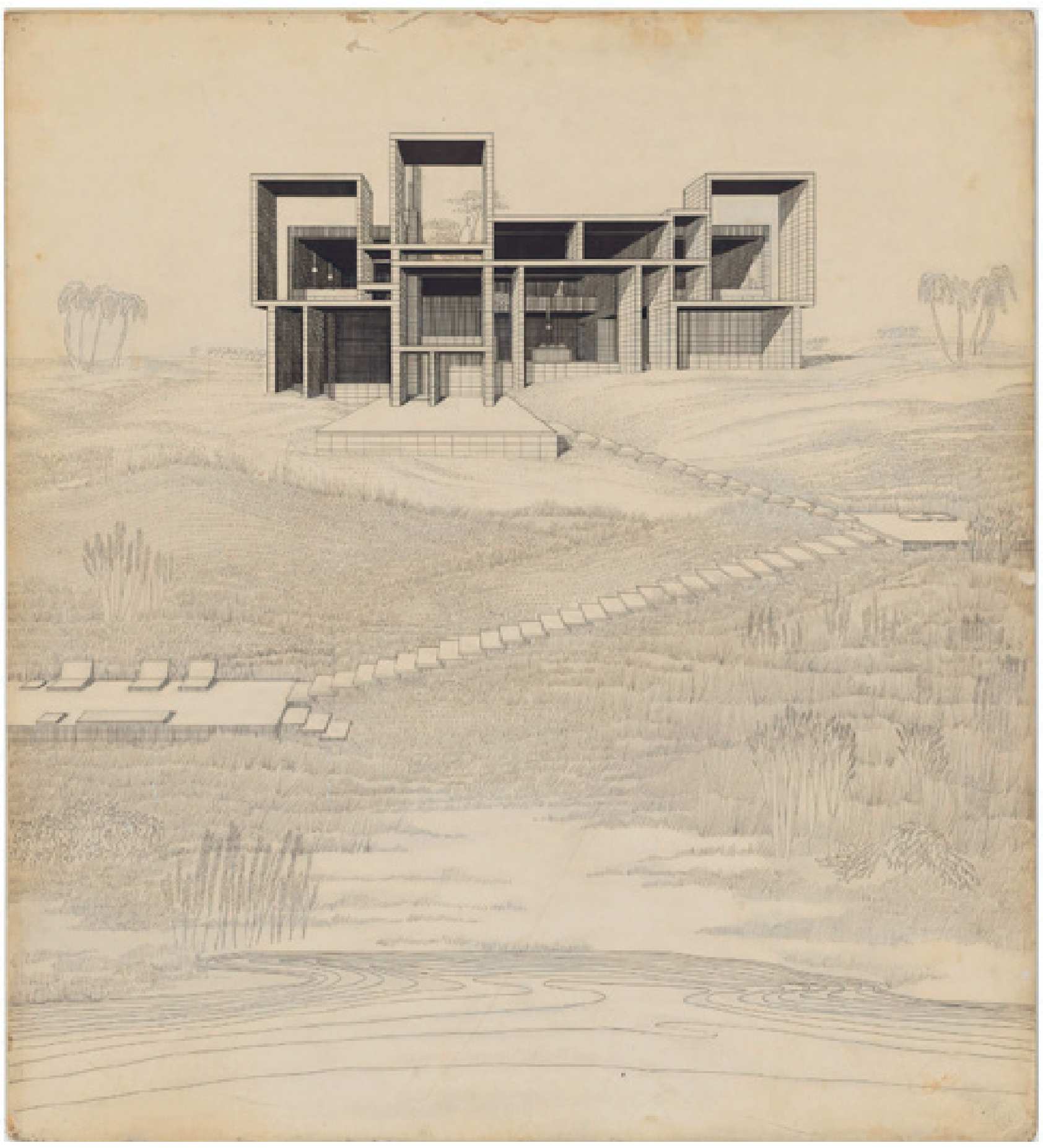

[Fig. 13] Paul Rudolph, Milam Residence,

Ponte Vedra Beach, Florida, 1960-62. Fuente:

Paul Rudolph Arthur W. Milam Residence,

Ponte Vedra Beach, Florida, Perspectiva ex-

terior desde la playa, 1960-62. Archivo online del MOMA 406.1985. 
[Fig. 14] Paul Rudolph. Cocoon House, Siesta Key, Florida, 1950. Fuente: Paul Rudolph. Cocoon House, Siesta Key, Florida, 1950. Archivo online del Library of Congress, Paul Marvin Rudolph Archives.

30 Es posible que Rudolph conociese las ideas de Church y las de su discípulo Garret Eckbo. Eckbo publica en 1950 "Landscape for Living" con gran repercusión. Se dice que al igual que el Donell Garden de Church era expresión de la época, este libro era el pequeño corpus de la teoría de la arquitectura del paisaje. Garret Eckbo, Landscape for living (Cambridge: University of Massachusetts Press, 1950), 129. Marc Treib, Garrett Eckbo: modern landscapes for living (Berkeley: University of California, 1997).

31 Peter Walker, Invisible gardens: the search for modernism in the American landscape (Cambridge: MIT Press, 1994), 96.

32 Paul Rudolph, "Regionalism in Architecture", Perspecta 4 (1957): 12-19.

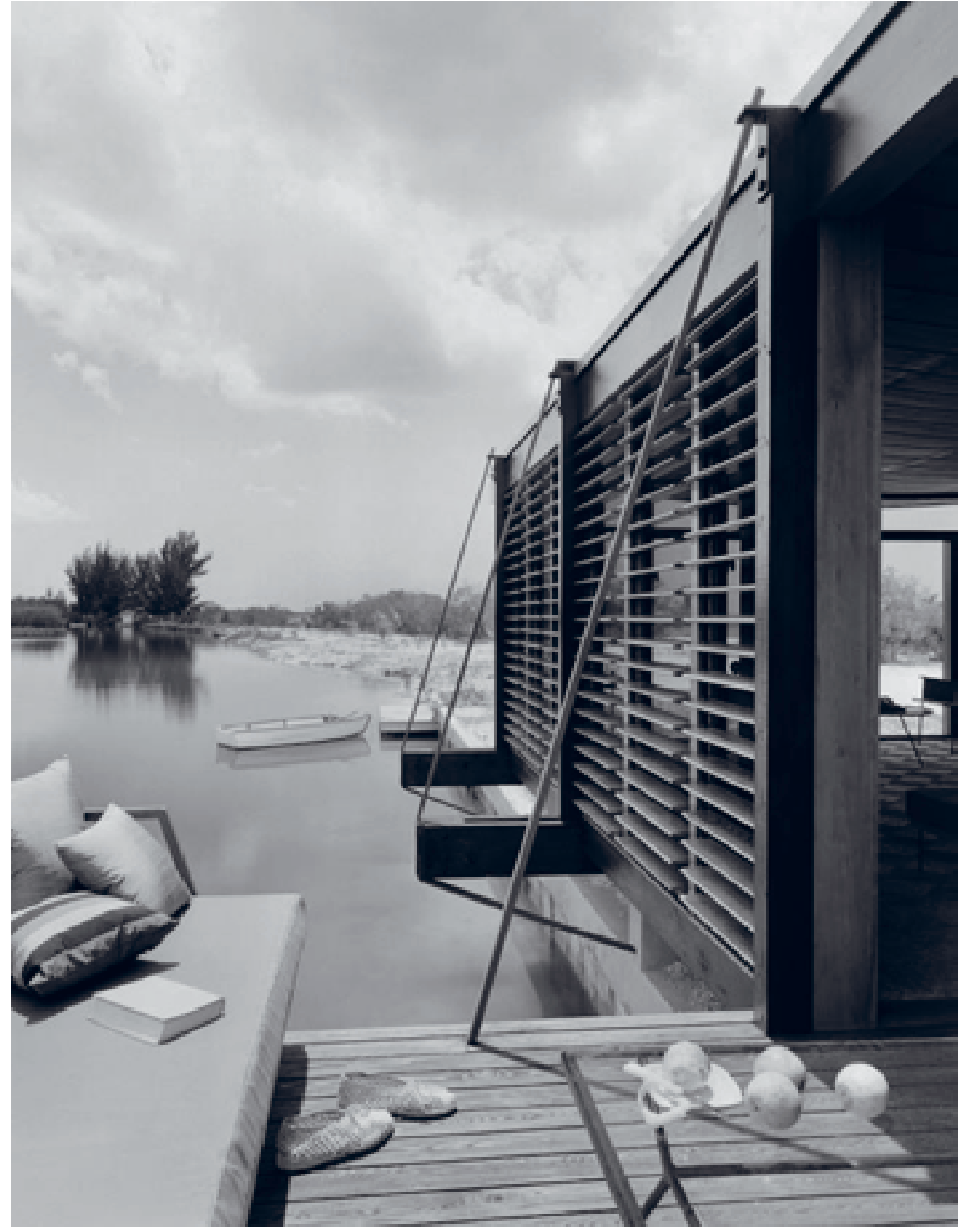

Rudolph, a través de sus dibujos, era capaz de redirigir la mirada hacia la arquitectura, utilizando distintos planos que van a superponerse para generar el efecto de la profundidad. Esto es lo que sucede en el famoso dibujo para la Casa Milam en Pontevedra Beach de 1962 [fig. 13]. El lugar se evoca mediante un juego de veladuras entre las que surge el edificio: naturaleza en primer plano, el terreno como un plano continuo y texturado, que nos conduce a través de una escalera diagonal hasta la línea del horizonte, donde sitúa la casa resaltada en tinta negra plana.

La Casa Milam es el inicio de un nuevo lenguaje formal en estas viviendas de Florida y posiblemente de la arquitectura doméstica de Rudolph. Su fachada entramada enfoca sus aperturas a una vida totalmente en contacto con el exterior. Se observa así el sincretismo de la obra de Rudolph y cómo su dibujo fue capaz de conformar la atmosfera de la arquitectura desde el papel.

\section{La experiencia del paisaje: a modo de conclusión}

Las tres visiones examinadas en relación entre arquitectura y paisaje son sólo algunas de las muchas vertientes de esta armonía inestable. La mejor conclusión a este texto sería el entendimiento de que el lugar no puede ser definido universalmente, que posee matices y sutilezas que hacen difícil establecer una idea consensuada.

En realidad, Paul Rudolph creó su ideal de lugar a través de su propia experiencia. Se insertó en una modernidad apropiada, donde su arquitectura se adapta a una 
112

ZARCH No. 10 | 2018

Centenarios

de la Tercera Generación

Centenaries of the

Third Generation

\section{NOELIA GALVÁN DESVAUX \\ ANTONIO ÁLVARO-TORDESILLAS \\ MARINA JIMÉNEZ JIMÉNEZ}

Paul Rudolph: arquitecturas dibujadas en el paisaje de Florida

Paul Rudolph: portrayed architectures

in Florida's landscape

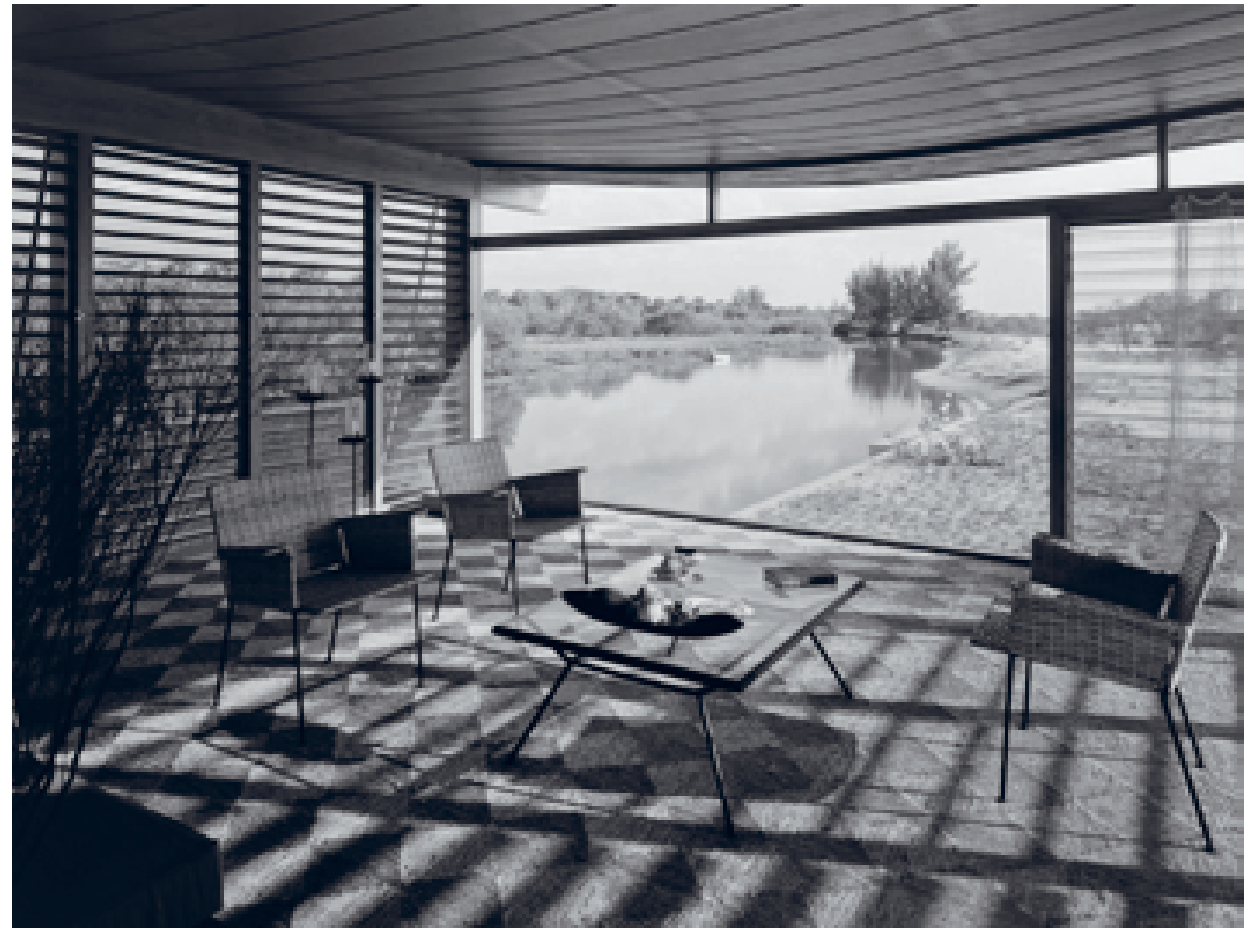

visión nueva marcada por los nuevos tiempos, por un modo de entender la arquitectura y de vivir el paisaje.

Thomas Church $^{30}$, el pionero del paisajismo americano, señaló en 1971 que lo que realmente quería la gente era poder percibir un sentimiento de relajación ${ }^{31}$. Un lugar para descansar de las tensiones del día, un mundo privado modelado y moldeado para las propias necesidades, deseos, caprichos. Esa sensación es la que se percibe en las imágenes de estas casas de Florida, como en las de la casa Cocoon, con su embarcadero sobre el agua y la veranda tamizada de luz [fig. 14 y 15]. Y esas aspiraciones son las que se también se descubren en sus dibujos.

Rudolph tenía la capacidad de mostrar espacios imaginados a través de sus manos, hasta tal punto que muchos de sus dibujos se asemejan tanto a las imágenes tomadas tras la construcción que reafirman la teoría aquí expuesta de la importancia del territorio y la implantación del proyecto en su obra. Sus proyectos son explicados con un discurso gráfico muy marcado que le distinguió en una época en la que existía una relación clara entre la arquitectura moderna y la adaptación al lugar ${ }^{32}$.

En sus casas de Florida desarrolló un sistema gráfico propio a medio camino entre el bucolismo romántico del paisaje y la búsqueda del rigor geométrico de su arquitectura. Creó lugares a través del dibujo, que se podían experimentar, pero, sobre todo, a través de una respuesta personal que surgió como entendimiento del lugar como transformación e integración, como dimensión poética de la naturaleza.

\section{Bibliografía}

Banham, Reyner. 1965. Convenient Benches and Handy Hooks: Functional Considerations in the Criticism of the Art of Architecture. En The History, Theory and Criticism of Architecture, Papers from the 1964 AIA-ACSA Teacher Seminar, ed. Marcus Whiffen, 92-105. Cambridge: MIT Press.

Bennion, Scott. 2013. In the manner of Hugh Ferriss and Paul Rudolph. RIBA Journal 120 (agosto): 33 . 
Bruegmann, Robert. 1986. Interview with Paul Rudolph. Chicago Architects Oral History Proyect, The Art Institute of Chicago. http://digital-libraries.saic.edu/cdm/ref/collection/caohp/id/9795

Del Rey Aynat, Miguel. 1999. De espacios y lugares en arquitectura. Vía arquitectura 6: 60.

Domin, Christopher. 2002. Paul Rudolph: the Florida houses. New York: Princeton.

Domingo, Débora. 2009. La modernidad sureña: Paul Rudolph en Florida. En Casa por casa: reflexiones sobre el habitar, W.AA., 90-103. (Valencia: General de Ediciones de Arquitectura).

Drew, Philip. 1972. Third Generation: The Changing Meaning of Architecture. London: Pall Mall Press.

Eckbo, Garret. 1950. Landscape for living. Cambridge: University of Massachusetts Press.

Frampton, Kenneth. 1983. Towards a Critical Regionalism: six points for an architecture of resistance. En The anti-aesthetic: essays on postmodern culture, ed. Hal Foster, 17-34. Seattle: Bay Press.

Futagawa, Yukio. 1977. Paul Rudolph: Architectural Drawings. Minnesota: Architectural Book Publishing.

Gideon, Sigfried. 1978. Espacio, tiempo y arquitectura. Madrid: Dossar.

Gray, Susan. 2001. Architects on Architects. New York: McGraw-Hill.

Heidegger, Martin. 1994. Conferencias y artículos. Barcelona: Ediciones del Serbal.

Howey, John. 1997. The Sarasota School of Architecture: 1941-1966. Cambridge: MIT Press.

Husserl, Edmund.1997. Ideas relativas a una fenomenología pura y una filosofía fenomenológica. Barcelona: Fondo de Cultura Económica.

Johnson, Philip y Stern, Robert A. M. 2008. The Philip Johnson Tapes: Interviews by Robert A.M. Stern. New York: Monacelli Press.

Jones, Cranston. 1961. Architecture Today and Tomorrow. New York: McGraw-Hill.

Malevich, Kazimir. 2013. El mundo no objetivo. Aracena: Gegner.

Navarro Baldewerg, Juan. 1999. La habitación vacante. Valencia: Pre-textos.

Norberg-Schulz, Christian. 1980. Genius loci: towards a phenomenology of architecture. Nueva York: Rizzoli International Publications.

Rohan, Timothy M. 2000. Rendering the Surface: Paul Rudolph's Art and Architecture Building at Yale. Grey Room 1 (otoño): 84-107.

2014. The Architecture of Paul Rudolph. Cambridge: Yale University Press.

Rudolph, Paul. 1956. The Six Determinants of Architectural Form. Architectural Record 120 (octubre):183-190.

1957. Regionalism in Architecture. Perspecta 4: 12-19.

Scarpa, Laurence. 2009. Paul Rudolph: Metaphors, Paradoxes, Contradictions and Abstractions, Cambridge: Yale Press.

Sitio web oficial de Sarasota History Alive. Siesta Key Architecture a Natural. http://www.sarasotahistoryalive.com/history/articles/siesta-key-architecture-a-natural/.

Sudjic, Deyan. 1999. Hogar: la casa del siglo XX. Barcelona: Blume.

Treib, Marc. 1997. Garrett Eckbo: modern landscapes for living. Berkeley: University of California.

Walker, Peter. 1994. Invisible gardens: the search for modernism in the American landscape. Cambridge: MIT Press.

Zinsser, John. 1985. Staying Creative; Artistic Passion Is a Lifelong Pursuit and These Mature Masters Prove the Point. (Otto Luening, Elizabeth Catlett, Paul Rudolph). 50 Plus 25 (diciembre): 49-55.

Zumthor, Peter. 2006. Atmosferas. Barcelona: Gustavo Gili. 